\title{
Association between R.E.N.A.L. nephrometry score and perioperative outcomes following open partial nephrectomy under cold ischemia
}

\author{
Dong Soo Park, MD; ;in Ho Hwang, MD; ${ }^{*}$ Moon Hyung Kang, MD;* Jong Jin Oh, MD
}

*Department of Urology, Seoul National University Bundang Hospital, Bundang-gu, Seongnam-si, Korea; 'Department of Urology, CHA Bundang Medical Center, CHA University, Bundang-gu, Seongnam-si, Korea

Cite as: Can Urol Assoc J 2014;8(3-4):e137-41. http://dx.doi.org/10.5489/cuaj.1372

Published online March 11, 2014.

\section{Abstract}

Introduction: We investigate the clinical significance of the R.E.N.A.L. nephrometry score for renal neoplasm following open partial nephrectomy (PN) under cold ischemia.

Methods: A retrospective analysis was conducted using clinical data of 98 consecutive patients with clear cell renal cell carcinoma who underwent open PN by a single surgeon from December 2000 to September 2012. Tumour complexity was stratified into 3 categories: low (4-6), moderate (7-9) and high (10-12) complexity. Perioperative outcomes, such as complications, cold ischemic time, estimated blood loss and renal function, were analyzed according to the complexity by NS. Complications were stratified using the Clavien-Dindo classification system.

Results: Tumour complexity according to nephrometry score was assessed as low in 16 (16.3\%), moderate in $48(49.0 \%)$ and high in $34(34.7 \%)$. The median cold ischemic time did not differ significantly among the 3 groups (36.0 minutes in low-, 40 minutes in moderate- and 43 minutes in the high-complexity group, $p=0.421)$. Total complications did not differ significantly $(2(2.0 \%)$ in low, $4(4.1 \%)$ in moderate and $4(4.1 \%)$ in high, $p=0.984)$. Each Grade 3 complication occurred in the moderate (urine leakage) and high groups (lymphocele). Postoperative renal functional outcomes were similar among the groups $(p=0.729)$. Only mean estimated blood loss was significantly different with nephrometry score $(p=0.049)$.

Conclusions: The nephrometry score, as used in an open PN series under cold ischemia, was not significantly associated with perioperative outcomes (i.e., ischemia time, complications, renal functional preservation).

\section{Introduction}

Detection and management of renal tumours are common for practicing urologists. ${ }^{1,2}$ The traditional standard of care is radical nephrectomy for a renal tumour. However, as new technologies and advanced imaging procedures develop, partial nephrectomy (PN) has become popular surgery for extracting renal tumours. PN has demonstrated oncological outcomes similar to radical nephrectomy with benefits in overall survival likely secondary to preservation of renal function. ${ }^{3,4}$

To better facilitate inter-physician communication and allow for more accurate case series comparisons in the literature, Kutikov and Uzzo devised the R.E.N.A.L. nephrometry scoring system. ${ }^{5}$ This scoring system has been proposed to characterize a renal tumour based on tumour radius, endophyticity level, nearness to collecting system, and location (R.E.N.A.L.). The R.E.N.A.L nephrometry score was developed based on what the authors believed were characteristics that rendered tumours more difficult to achieve PN. ${ }^{6}$ Since its introduction, the R.E.N.A.L. nephrometry score has shown its prognostic capability with respect to postoperative outcomes, such as reducing warm ischemic time and reducing surgery-related complications. ${ }^{7,8}$ However, there is some debate on whether it can predict renal functional outcomes and surgery-related outcomes. ${ }^{6,9-11}$ Moreover, these studies mostly applied to the patients who underwent robotic partial nephrectomy (RPN) or laparoscopic partial nephrectomy (LPN), minimally invasive surgeries that used warm ischemia methods. In this study, we applied the nephrometry score to patients who underwent open partial nephrectomy (OPN) with cold ischemia and we confirm the usefulness of the nephrometry score to confirm postoperative outcomes.

\section{Methods}

\section{Study population}

We consulted our prospectively maintained institutional kidney centre database, after we obtained approval by our Institutional Review Board. We identified all patients from December 2000 to September 2012 who underwent PN with available cross-sectional imaging by computerized tomography (CT) for assessment. We excluded patients 
Park et al.

who had solitary kidney, chronic kidney insufficiency and previous kidney surgery. We also excluded patients with benign lesions or non-clear cell renal cell carcinoma (RCC). In the end, we included 98 patients who underwent OPN under cold ischemia. The surgical technique for OPN, as previously reported, was used in all patients. ${ }^{12}$ The secure reconstruction technique was applied using a combination of expanded polytetrafluoroethylene and Hem-O-Lok (Weck Surgical Instruments, Teleflex Medical, Durham, NC) to reduce surgery-related complications.

\section{Evaluation}

Preoperative CT imaging was reviewed in the axial and coronal planes, and a nephrometry score was assigned to all identified lesions, as described by Kutikov and Uzzo. ${ }^{5}$ All score assignments were performed by at least 2 investigators with conflicting data reviewed. Each tumour was scored for total nephrometry score and for each of its individual subcategories. The nephrometry score was categorized as low (4-6 points), moderate (7-9 points) or high (10-12 points) complexity. The perioperative outcomes, such as complications, cold ischemic time, estimated blood loss and renal functional outcomes, were analyzed according to the stratification of complexity by nephrometry score. Intra- and postoperative complications were stratified using the Clavien-Dindo classification system. ${ }^{13}$

\section{Statistical analysis}

Demographic and clinical characteristics were compared between tumour complexity groups. Continuous variables were analyzed by Wilcoxon tests, and categorical variables were examined by chi-square analyses. Statistical analyses were carried out using SPSS version 15.0 software (Statistical Package for Social Sciences, Chicago, IL). Two-tailed null hypotheses of no difference were rejected if $p$ values were less than 0.05 .

\section{Results}

The mean age of all study subjects was 53.8 , the mean tumour size was $3.87 \mathrm{~cm}$ and the mean cold ischemic time was 42.5 minutes (Table 1). Patients were followed for a median 47.5 months. There were 16 (16.3\%), 48 (49.0\%), 34 $(34.7 \%)$ patients in the low-, moderate- and high-complexity group, respectively. Tumour size was significantly larger by complexity grade: $2.78 \mathrm{~cm}, 3.55 \mathrm{~cm}$ and $4.85 \mathrm{~cm}$ in the low-, moderate-, and high-complexity groups, respectively. There were no significant differences with respect to age, gender and body mass index. In terms of operative data, total operation time and cold ischemic time were not significantly different among the case series. The cold ischemic time was 38.8 minutes, 44.1 minutes and 45.4 minutes in the low-, moderate-, and high-complexity groups, respectively. Only estimated blood loss was higher by complexity grade (195 vs. 261 vs. 285 cc, low vs. moderate vs. high, respectively). No radical conversion was reported. All pathological types of tumour among subjects were clear cell RCC: T1a was 84 $(85.7 \%), \mathrm{T} 1 \mathrm{~b}$ was $8(8.2 \%)$, T2 was $1(1.0 \%)$ and T3a was 5 (5.1\%). Pathological T1b and T2 tumour were significantly included in higher complexity group; however, there was no significant difference of Fuhrman grade according to tumour complexity.

\begin{tabular}{|c|c|c|c|c|c|}
\hline & All patients & $\begin{array}{l}\text { Low complexity } \\
\text { group }\end{array}$ & $\begin{array}{c}\text { Moderate complexity } \\
\text { group }\end{array}$ & $\begin{array}{l}\text { High complexity } \\
\text { group }\end{array}$ & $p$ value \\
\hline Nephrometry score & & $4-6$ & $7-9$ & $10-12$ & \\
\hline N (\%) & 98 & $16(16.3)$ & $48(49.0)$ & $34(34.7)$ & \\
\hline Age, year \pm SD & $53.8 \pm 12.6$ & $59.6 \pm 11.3$ & $53.7 \pm 11.8$ & $51.1 \pm 13.8$ & 0.084 \\
\hline Gender, n (\%) & & & & & 0.784 \\
\hline Male & $58(59.2)$ & $13(81.3)$ & $29(60.4)$ & $16(47.1)$ & \\
\hline Female & $40(40.8)$ & $3(18.7)$ & 19 (39.6) & $18(52.9)$ & \\
\hline $\mathrm{BMI}, \mathrm{kg} / \mathrm{m}^{2} \pm \mathrm{SD}$ & $24.4 \pm 2.4$ & $24.2 \pm 2.6$ & $24.4 \pm 2.2$ & $24.6 \pm 2.8$ & 0.164 \\
\hline Preoperative tumour size $(\mathrm{cm})$ & $3.87 \pm 3.17$ & $2.78 \pm 1.42$ & $3.55 \pm 1.40$ & $4.85 \pm 4.93$ & 0.006 \\
\hline Median follow-up, months & $47.5 \pm 11.3$ & $53.6 \pm 7.8$ & $44.5 \pm 3.8$ & $48.6 \pm 12.3$ & 0.881 \\
\hline \multicolumn{6}{|l|}{ Operative data } \\
\hline Estimated blood loss, mL & $263.7 \pm 140.1$ & $195.0 \pm 74.1$ & $261.1 \pm 87.1$ & $285.1 \pm 110.3$ & 0.049 \\
\hline Ischemic time, $\min$ & $42.5 \pm 15.6$ & $36.3 \pm 15.9$ & $40.1 \pm 12.6$ & $43.4 \pm 11.3$ & 0.421 \\
\hline Operative time, $\min$ & $183 \pm 13.4$ & $167 \pm 23.8$ & $180.1 \pm 22.3$ & $178.5 \pm 37.9$ & 0.191 \\
\hline Pathologic stage (T1a/T1b/T2/T3a) & $84 / 8 / 1 / 5$ & $15 / 0 / 0 / 1$ & $45 / 2 / 0 / 2$ & $24 / 6 / 1 / 2$ & 0.037 \\
\hline Furhman grade $(1 / 2 / 3 / 4)$ & $4 / 50 / 38 / 6$ & $1 / 9 / 6 / 0$ & $1 / 25 / 19 / 3$ & $2 / 16 / 13 / 3$ & 0.500 \\
\hline Positive surgical margin, (\%) & $2(2.0)$ & 0 & $1(1.0)$ & $1(1.0)$ & 0.781 \\
\hline
\end{tabular}

SD: standard deviation; BMI: body mass index. 
R.E.N.A.L. score in open nephrectomy under cold ischemia

Among the 98 patients, there were 11 complications (Table 2$)$. Two $(2.0 \%)$ were in the low complexity group, and $4(3.1 \%)$ in the moderate and high complexity groups. Nine complications were Clavien-Dindo classification I and II; there were only $2 \geq 3$ grade complications. In the low complexity group, all 2 complications were wound cellulitis. In the moderate complexity group, there were 4 complications: 1 persistent hematuria, 1 wound cellulitis, 2 bleeding requiring transfusion and 1 lymphocele requiring percutaneous drainage under interventional therapy. In the high complexity group, there were also 4 complications: 1 persistent hematuria, 2 bleeding requiring transfusion and 1 urinary leakage requiring ureteral stent insertion. There were no significant differences in terms of complications by tumour complexity grade.

Table 3 presents postoperative renal functional outcomes. There was no significant difference of preoperative estimated glomerular filtration rate (eGFR) or serum creatinine. After OPN, postoperative eGFR and serum creatinine were similar at 1 month and 6 months. The change of eGFR and serum creatinine was also similar among the case series.

\section{Discussion}

In the current study, we observed that nephrometry score applied to OPN series under cold ischemia was not significantly associated with perioperative outcomes, espe-

\begin{tabular}{|c|c|c|c|c|}
\hline & $\begin{array}{l}\text { Low } \\
\text { complexity } \\
\text { group }\end{array}$ & $\begin{array}{l}\text { Moderate } \\
\text { complexity } \\
\text { group }\end{array}$ & $\begin{array}{c}\text { High } \\
\text { complexity } \\
\text { group }\end{array}$ & $p$ value \\
\hline $\begin{array}{l}\text { Nephrometry } \\
\text { score }\end{array}$ & $4-6$ & $7-9$ & $10-12$ & \\
\hline N (\%) & $16(16.3)$ & $48(49.0)$ & $34(34.7)$ & \\
\hline $\begin{array}{l}\text { No. } \\
\text { complications } \\
(\%)\end{array}$ & $2(2.0 \%)$ & $4(4.1 \%)$ & $4(4.1 \%)$ & 0.984 \\
\hline \multicolumn{5}{|l|}{$\begin{array}{l}\text { Clavien-Dindo } \\
\text { class I }\end{array}$} \\
\hline $\begin{array}{l}\text { Persistent } \\
\text { hematuria }\end{array}$ & 0 & $1(1.0 \%)$ & $1(1.0 \%)$ & 0.874 \\
\hline $\begin{array}{l}\text { Wound } \\
\text { cellulitis }\end{array}$ & $2(2.0 \%)$ & $1(1.0 \%)$ & 0 & 0.474 \\
\hline \multicolumn{5}{|l|}{$\begin{array}{l}\text { Clavien-Dindo } \\
\text { class II }\end{array}$} \\
\hline $\begin{array}{l}\text { Bleeding } \\
\text { requiring } \\
\text { transfusion }\end{array}$ & 0 & $2(2.0 \%)$ & $2(2.0 \%)$ & 0.678 \\
\hline \multicolumn{5}{|l|}{$\begin{array}{l}\text { Clavien-Dindo } \\
\text { class III-VI }\end{array}$} \\
\hline Urine leakage & 0 & 0 & $1(1.0 \%)$ & 0.477 \\
\hline Lymphocele & 0 & $1(1.0 \%)$ & 0 & 0.674 \\
\hline
\end{tabular}

cially ischemic time, complications and postoperative renal functional preservation among a consecutive case series of Korean men.

Advanced image techniques have led to a marked increase in the number of incidentally discovered small renal masses. ${ }^{14}$ Migration of stage has allowed less invasive surgery, including LPN. PN has equivalent disease-specific outcomes compared with $\mathrm{RN}$, with improved renal functional outcomes. ${ }^{15,16}$ Unfortunately, LPN is considerably more challenging, with parameters that predict surgical difficulty before the actual surgery. Therefore, nephrometry score might be introduced in the era of LPN because the PN surgical approach does not effectively reduce ischemic time.

Several previous studies of the correlation of nephrometry score with ischemic time showed mostly positive associations, especially from LPN or RPN case series. Hayn and colleagues concluded that a higher nephrometry score was significantly associated with an increased warm ischemic time in their LPN case series. ${ }^{17}$ In their RPN series, Png and colleagues showed that complex tumours with a higher nephrometry scores had significantly high ischemic times compared with non-complex tumours. ${ }^{11}$ In their minimally invasive PN case series, Liu and colleagues ${ }^{18}$ and Altunrende and colleagues ${ }^{9}$ found that nephrometry score was predictive of warm ischemic time, and mean warm ischemic time increased significantly by tumour complexity. Some data from OPN series also showed positive correlation of nephrometry score with warm ischemic time. Long and colleagues found that among patients who mostly under-

\begin{tabular}{|c|c|c|c|c|}
\hline & $\begin{array}{c}\text { Low } \\
\text { complexity } \\
\text { group }\end{array}$ & $\begin{array}{c}\text { Moderate } \\
\text { complexity } \\
\text { group }\end{array}$ & $\begin{array}{c}\text { High } \\
\text { complexity } \\
\text { group }\end{array}$ & $p$ value \\
\hline $\begin{array}{l}\text { Nephrometry } \\
\text { score }\end{array}$ & $4-6$ & $7-9$ & $10-12$ & \\
\hline \multicolumn{5}{|l|}{ Mean \pm SD } \\
\hline $\begin{array}{l}\text { Preoperative } \\
\text { eGFR }\end{array}$ & $72.2 \pm 25.3$ & $72.9 \pm 19.9$ & $77.9 \pm 25.3$ & 0.592 \\
\hline Preoperative $\mathrm{Cr}$ & $1.04 \pm 0.26$ & $1.02 \pm 0.22$ & $1.03 \pm 0.55$ & 0.982 \\
\hline $\begin{array}{l}\text { Postoperative } 1 \\
\text { month eGFR }\end{array}$ & $72.6 \pm 27.6$ & $72.6 \pm 18.1$ & $77.9 \pm 26.9$ & 0.588 \\
\hline $\begin{array}{l}\text { Postoperative } 1 \\
\text { month } \mathrm{Cr}\end{array}$ & $1.05 \pm 0.26$ & $1.02 \pm 0.24$ & $1.01 \pm 0.49$ & 0.951 \\
\hline $\begin{array}{l}\text { Change in eGFR } \\
\text { at } 1 \text { month }\end{array}$ & 0.40 & -0.30 & 0 & 0.974 \\
\hline $\begin{array}{l}\text { Postoperative } 6 \\
\text { months eGFR }\end{array}$ & $67.5 \pm 23.5$ & $72.8 \pm 20.3$ & $70.1 \pm 23.2$ & 0.729 \\
\hline $\begin{array}{l}\text { Postoperative } 6 \\
\text { months } \mathrm{Cr}\end{array}$ & $1.07 \pm 0.33$ & $1.04 \pm 0.24$ & $1.13 \pm 0.54$ & 0.726 \\
\hline $\begin{array}{l}\text { Change in eGFR } \\
\text { at } 6 \text { months }\end{array}$ & -4.7 & -0.10 & -7.8 & 0.367 \\
\hline
\end{tabular}


Park et al.

went OPN, the nephrometry score predicted increased risk of prolonged warm ischemic time..$^{10}$ In their OPN series, Lavallee and colleagues found that several parameters of tumour complexity positive correlated with warm ischemic time.${ }^{19}$ However, Mufarrij and colleagues demonstrated that nephrometry-graded tumour complexity was not related to warm ischemic time for 92 patients who underwent RPN. ${ }^{20}$ Their interpretation was that since their series was based on the skills of a highly experienced laparoscopic and robotic surgeons, differences between simple and complex cases were too minuscule to detect. They also cited several selection biases. Our analysis was the first report of the correlation of nephrometry score with ischemic time in OPN under cold ischemia. In cold ischemia, there is little time pressure compared with warm ischemia. In a PN series, ischemic time is usually accepted as the parameter for evaluating operative outcomes, 30 minutes or less has historically been used as the warm ischemic time. ${ }^{21}$ More recently, other studies proposed a 20-minute cut-off. ${ }^{22,23}$ Because of this tight time limit in $\mathrm{PN}$ and the need to speed up the procedure, there were several complications. Recent studies showed that most PN used warm ischemia. As laparoscopic and robotic $\mathrm{PN}$ procedures were introduced, warm ischemia was standard practice worldwide (and even applied in OPN). The range of safe warm ischemic time should be less than 20 or 30 minutes for controlling postoperative renal function or complications. ${ }^{22.23}$ Although renal functional preservation should be based on normal function of the contralateral kidney, actual postoperative renal function after $\mathrm{PN}$ was assessed by renal functional volumetric change. ${ }^{2}$ Because the nephrometry score had a factor of tumoural volume representing tumoural diameter, some reports in which higher nephrometry score was associated with poorer renal functional outcome following PN had adequate evidence. ${ }^{24}$ If the same renal functional volume is lost, we should use cold ischemia in PN. In situ renal hypothermia is used to protect against ischemic renal injury. Surface cooling of the kidney with ice slush allows up to 3 hours of safe ischemia without permanent renal injury. ${ }^{25,26}$ Therefore our analysis from PN case series using cold ischemic type showed no significant difference of ischemic time according to nephrometry score grade, because there was no real time pressure even with a large-sized tumour.

Concerning complications, there were controversial conclusions. Stroup and colleagues showed that nephrometry score was associated with urine leak in the Mayo clinic database. ${ }^{27}$ Rosevear and colleagues concluded that nephrometry score was a significant predicting factor for complication after PN among 91 patients. Simhan and colleagues also showed that increases of renal complexity were associated with the development of major complications after PN among 390 consecutive patients. ${ }^{28}$ However, Long and colleagues ${ }^{10}$ confirmed the link between nephrometry score and complication risk; there was no significant correlation of nephrometry score with complication risk among the mainly OPN series. In their RPN series, Png and colleagues showed similar complication rates between complex and non-complex tumours. In our results, we observed no significant difference among nephrometry scores. We found that by using cold ischemia, we had spare time during surgery to allow for more delicate procedures, such as renal reconstruction or repair of the collecting system. Especially in our series, we were able to use secure reconstruction techniques using Gore-Tex and Hem-o-Lok (Dupont). ${ }^{12}$ This may have led to the low complication rate in the total case series, and no significant differences according to nephrometry score grade.

Our study had several limitations. We had a sample number disparity according to nephrometry score; only $16.3 \%$ of 98 patients were included in the low complexity tumour grade. This data from our kidney centre database were consecutive data, so further study is needed to adjust for sample size in each NS group. Another limitation was the relatively low total complication rate. Although more secure techniques were performed in all patients, there was the possibility of false negative effects due to relatively small cohort. Another limitation was that we could not adjust contralateral kidney function. If we had known the actual effect of renal function after $\mathrm{PN}$ according to tumour complexity, this might be used in a solitary kidney case series or for adjusting contralateral kidney function. However, we could not do this practically. Further evaluation about this topic should be conducted via prospective well-controlled randomized studies, while adjusting for other factors. Another limitation was that we could not control other medical problems or medication history that might affect renal function preoperatively due to the retrospective design. We minimized other limitations by collecting only clear cell RCC data from a single surgeon's database, measuring the nephrometry score for each patient by a single urologist. Further study is needed to estimate the association of tumour complexity with malignancy among all kidney centre databases similar to the study by Mullins and colleagues. ${ }^{29}$

\section{Conclusion}

OPN under cold ischemia was safely performed regardless of tumour complexity. Applying nephrometry score to an OPN series under cold ischemia was not significantly associated with perioperative outcomes. The cold ischemia time, complication rate and renal functional outcomes after PN was similar by nephrometry score grade. To minimize complications, renal functional loss and other surgery-related hazards regardless of tumour complexity, $\mathrm{PN}$ with cold ischemia is recommended. 
R.E.N.A.L. score in open nephrectomy under cold ischemia

Competing interests: Dr. Park, Dr. Hwang, Dr. Kang and Dr. Oh all declare no competing financial or personal interests.

This paper has been peer-reviewed.

\section{References}

1. Jemal A, Siegel R, Ward E, et al. Cancer statistics, 2008. CA Cancer J Clin 2008;58:71-96. http:// dx.doi.org/10.3322/CA.2007.0010

2. Mathew A, Devesa SS, Fraumeni JF Jr, et al. Global increases in kidney cancer incidence, 1973-1992. Eur J Cancer Prev 2002;11:171-8. http://dx.doi.org/10.1097/00008469-200204000-00010

3. Rini BI, Campbell SC, Escudier B. Renal cell carcinoma. Lancet 2009;373:1119-32. http://dx.doi. org/10.1016/S0140-6736(09)60229-4

4. Campbell SC, Novick AC, Belldegrun A, et al. Guideline for management of the clinical $\mathrm{Tl}$ renal mass. J Urol 2009;182:1271-9. http://dx.doi.org/10.1016/i.juro.2009.07.004

5. Kutikov A, Uzzo RG. The R.E.N.A.L. nephrometry score: A comprehensive standardized system for quantitat ing renal tumour size, location and depth. J Urol 2009;182:844-53. http://dx.doi.org/10.1016/i. juro.2009.05.035

6. Bruner $B$, Breau RH, Lohse $C M$, et al. Renal nephrometry score is associated with urine leak after partial nephrectomy. BJU Int 2011;108:67-72. http://dx.doi.org/10.1111/i.1464-410X.2010.09837.x

7. Canter D, Kutikov A, Manley B, et al. Utility of the R.E.N.A.L. nephrometry scoring system in objectifying treatment decision-making of the enhancing renal mass. Urology 2011;78:1089-94. http://dx.doi. org/10.1016/i.urology.2011.04.035

8. Rosevear HM, Gellhaus PT, Lightfoot AJ, et al. Utility of the RENAL nephrometry scoring system in the real world: predicting surgeon operative preference and complication risk. BJU Int 2012;109:700-5. http:// dx.doi.org/10.1111/i.1464-410X.2011.10452.x

9. Altunrende $F$, Laydner $\mathrm{H}$, Hernandez AV, et al. Correlation of the RENAL nephrometry score with warm ischemia time after robotic partial nephrectomy. World J Urol 2012;31:1165-9. http://dx.doi.org/10.1007/ s00345-012-0867-4. Epub 2012 Apr 19

10. Long JA, Arnoux V, Fiard $G$, et al. External validation of the RENAL nephrometry score in renal tumours treated by partial nephrectomy. BJU Int 2013;111:233-9. http://dx.doi.org/10.1111/i.1464410X.2012.11339.x

11. Png KS, Bahler CD, Milgrom DP, et al. The role of R.E.N.A.L. Nephrometry Score in the era of robot assisted partial nephrectomy. J Endourol 2013;27:304-8. http://dx.doi.org/10.1089/end.2012.0182. Epub 2013 Feb 14

12. Park DS, Jang WK. Secure reconstruction technique after partial nephrectomy irrespective of tumour size and location. Int Braz J Urol 2009;35:416-26. http://dx.doi.org/10.1590/S1677-55382009000400004

13. Dindo D, Demartines N, Clavien PA. Classification of surgical complications: a new proposal with evaluation in a cohort of 6336 patients and results of a survey. Ann Surg 2004;240:205-13. http://dx.doi. org/10.1097/01.sla.0000133083.54934.ae

14. Lee CT, Katz J, Shi W, et al. Surgical management of renal tumour $s 4 \mathrm{~cm}$. or less in a contemporary cohort. J Urol 2000;163:730-6. http://dx.doi.org/10.1016/S0022-5347(05)67793-2
15. Uzzo RG, Novick AC. Nephron sparing surgery for renal tumour s: indications, techniques and outcomes. J Urol 2001;166:6-18. http://dx.doi.org/10.1016/S0022-5347(05)66066-1

16. Fergany AF, Hafez KS, Novick AC. Long-term results of nephron sparing surgery for localized renal cell carcinoma: 10-year follow-up. J Urol 2000;163:442-5. http://dx.doi.org/10.1016/S0022$5347(05) 67896-2$

17. Hayn MH, Schwaab T, Underwood W, et al. RENAL nephrometry score predicts surgical outcomes of laparoscopic partial nephrectomy. BJU Int 2011;108:876-81.

18. Liu ZW, Olweny EO, Yin G, et al. Prediction of perioperative outcomes following minimally invasive partial nephrectomy: Role of the R.E.N.A.L nephrometry score. World J Urol 2012;31:1183-9. http://dx.doi. org/10.1007/s00345-012-0876-3. Epub 2012 Apr 28.

19. Lavallee LT, Desantis D, Kamal F, et al. The association between renal tumour scoring systems and ischemia time during open partial nephrectomy. Can Urol Assoc J 2012;15:1-8. http://dx.doi.org/10.5489/ cuaj.11202

20. Mufarrii PW, Krane $L S$, Rajamahanty $S$, et al. Does nephrometry scoring of renal tumour s predict outcomes in patients selected for robot-assisted partial nephrectomy? J Endourol 2011;25:1649-53. http://dx.doi. org/10.1089/end.2011.0003

21. Novick AC. Renal hypothermia: In vivo and ex vivo. Urol Clin North Am 1983;10:637-44.

22. Becker $\mathrm{F}$, Van Poppel $\mathrm{H}$, Hakenberg OW, et al. Assessing the impact of ischaemia time during partial nephrectomy. Eur Urol 2009;56:625-34. http://dx.doi.org/10.1016/i.eururo.2009.07.016

23. Thompson RH, Leibovich $B C$, Lohse $C M$, et al. Complications of contemporary open nephron sparing surgery: a single institution experience. J Urol 2005;174:855-8. http://dx.doi.org/10.1097/01. ju.0000169453.29706.42

24. Cha EK, $\mathrm{Ng} \mathrm{CK}$, Jeun B, et al. Preoperative radiographic parameters predict long-term renal impairment following partial nephrectomy. World J Urol 201 1;31:817-22. http://dx.doi.org/10.1007/s00345011-0694-z. Epub 2011 May 21.

25. Tatsugami K, Eto M, Yokomizo A, et al. Impact of cold and warm ischemia on postoperative recovery of affected renal function after partial nephrectomy. J Endourol 2011;25:869-73. http://dx.doi. org/10.1089/end.2010.0502

26. Lane BR, Russo P, Uzzo RG, et al. Comparison of cold and warm ischemia during partial nephrectomy in 660 solitary kidneys reveals predominant role of nonmodifiable factors in determining ultimate renal function. J Urol 2011;185:421-7. http://dx.doi.org/10.1016/i.juro.2010.09.131

27. Stroup SP, Palazzi K, Kopp RP, et al. RENAL nephrometry score is associated with operative approach for partial nephrectomy and urine leak. Urology 2012;80:151-6. http://dx.doi.org/10.1016/j.urology.2012.04.026

28. Simhan J, Smaldone MC, Tsai KJ, et al. Objective measures of renal mass anatomic complexity predict rates of major complications following partial nephrectomy. Eur Urol 2011;60:724-30. http://dx.doi. org/10.1016/i.eururo.2011.05.030

29. Mullins JK, Kaouk JH, Bhayani S, et al. Tumour complexity predicts malignant disease for small renal masses. J Urol 2012;188:2072-6. http://dx.doi.org/10.1016/i.juro.2012.08.027

Correspondence: Dr. Jong Jin Oh, Department of Urology, Seoul National University Bundang Hospital, 300, Gumi-dong, Bundang-gu, Seongnam-si, Kyunggi-do, Korea 463-707; bebsuzzang@naver.com 